\title{
Evaluating the durability of recycled concrete made of coarse recycled aggregate concrete containing silica-fume and natural zeolite
}

\author{
Hasan Jalilifar (Main Author) \\ Department of Civil Engineering, Ahvaz Branch, Islamic Azad University \\ Ahvaz (Iran) \\ aba@aut.ac.ir \\ https://orcid.org/0000-0002-4487-4653 \\ Fathollah Sajedi (Corresponding Author) \\ Department of Civil Engineering, Ahvaz Branch, Islamic Azad University \\ Ahvaz (Iran) \\ sajedi@iauahvaz.ac.ir \\ https://orcid.org/0000-0003-3933-2793 \\ Vahid Razavi Toosi \\ Department of Civil Engineering, Ahvaz branch, Islamic Azad University \\ Ahvaz (Iran) \\ razavi@jsu.ac.ir
}

Manuscript Code: 14080

Date of Acceptance/Reception: 10.08.2020/09.09.2019

DOI: 10.7764/RDLC.19.3.457

\begin{abstract}
Although the mechanical properties of recycled aggregates concrete (RAC's) are well known, the durability properties of these concretes are less agreed upon by researchers. The main objective of this paper is to evaluate the durability of RAC's made of recycled concrete coarse aggregate (RCCA) containing silica-fume (SF) and natural zeolite (NZ). Four series of mixtures were made using four levels of RCCA as $0 \%, 25 \%, 50 \%$, and $100 \%$ with natural coarse aggregates (NCA's). SF with $5 \%, 10 \%$, and $15 \%$ and NZ with $10 \%, 20 \%$, and $30 \%$ were replaced with cement. To evaluate the durability properties of RAC's, 28 mixed design were made and compressive strength (CS), water absorption by immersion (WAI), water absorption by capillary (WAC), electrical resistance (ER), electrical conductivity (EC), and rapid chloride ion penetration test (RCPT) were measured. The results showed that WAI and WAC of RAC increased with enhancing the RCCA level. By increasing the replacement level of RCCA, and usage of 10\% SF replacement showed a greater impact on improving CS. Concretes containing NZ had higher WAI than that of SF. The increasing level of NZ by more than $10 \%$, increases the space of cavities between silicate gels and therefore increases WAC in concretes. With increasing in the RCA level, so did the EC of RAC; however, EC in pozzolanic concretes showed a lower growth rate by increasing the RCCA level. Using $25 \%$ of RCCA, and $10 \%$ of SF, it was possible to make concrete with very low chloride ion penetration.
\end{abstract}

Keywords: recycled concrete; recycled aggregate; durability; silica-fume (SF); natural zeolite (NZ).

Today, the construction industry needs more than ever to look at sustainable development. Consumption of more than $50 \%$ of nature's raw materials, $40 \%$ of all energy and the production of $50 \%$ of the world's waste (Oikonomou, 2005), along with the devastating environmental impact of construction and demolition waste (CDW), shows the importance of paying attention to sustainable development options in this industry. In this approach, recycling is one of the most likely options that has attracted the attention of various countries. However, a relatively similar approach is not observed among countries in this regard. Among developed countries, countries such as Japan, Germany, and the Netherlands have a recycling rate of more than $80 \%$, while many other developed countries have a recycling rate of between $20 \%$ and $40 \%$ (Kisku et al., 2017). Developing countries also have a very small impact on this approach, so that the recycling rate of construction materials in a country like Iran is very small, while the average annual waste production in its capital (Tehran) is about 18 million tons.

The adhered mortar is an important factor in determining the quality of recycled aggregate (RA) by the reduction in the density, the increase in water absorption, and the reduction of abrasion resistance (Sasanipour and Aslani, 2020). This reduction in quality has an impressive effect on the mechanical and durability properties of RC including CS, modulus of elasticity (ME), and resistance to the penetration of corrosive ions. Since there has been relative agreement on the mechanical properties of RAC, compared to the mechanical properties, limited attempts have been made to assess the 
durability properties of RC and less consensus has been reached. Due to the permeable nature of RA, which is known to decrease resistance to chloride and sulfate ions penetration [Hobbs, 1999). There is a consensus in the literature review that, as the RA replacement level increases, so does the chloride and sulfate ions penetration (Kou \& Poon, 2009; Kou \& Poon, 2012; Tu et al., 2005).

Several researchers have been tried to reduce the adverse effect of RA on the durability of RAC. For example, to increase the density and fill the pores and micro-cracks of RA, Tam et al. (2005) recommend a two-stage mixing approach (TSMA) and immerse the RA into the supplementary cementitious materials (SCM) slurry. The authors reported that $100 \%$ RCCA specimens made with the TSMA exhibited an $11 \%$ lower total charge passed than those of the same mixes using the normal mixing approach (NMA). Kong et al. (2010) proposed another procedure, similar to the TSMA, but with a new stage, in which the aggregates in saturated surface-dried condition are mixed with mineral additions. This method allowed producing RAC mixes with equivalent mechanical properties and total charge passed when compared with the conventional concrete (CC) made with the NMA. Zhu et al. (2013) reported that Immersion of RA in a high-adhesion polymer emulsion and its penetration into the pores of RA leads to an increase in adhesion resistance between the attached mortar and the aggregate and reduce the water absorption of RAC. In contrast to the aforementioned successful methods, favorable results were not reported by some methods. For example, Akbarnezhad et al. (2013) examined pre-soaking the $\mathrm{RA}$ in $\mathrm{H}_{2} \mathrm{SO}_{4}$ and $\mathrm{HCl}$ to remove the attached mortar. They have shown that the effectiveness of this method depends on several factors such as the porosity of the RA, the type, amount, and concentration of the acid and the environment temperature. Also, the authors concluded that using this method increases the possibility of increasing the amount of sulfate and chloride in the RA and this will directly affect the durability of RAC.

It is an accepted fact that replacing SCMs with Portland cement has environmental benefits in addition to reducing construction costs $(\mathrm{Wu}, 2017)$. Researchers have reported that SCMs can improve the mechanical properties and durability properties of concrete at the optimum replacement level by their filler and pozzolanic properties (Hannesson et al. 2012; Pan et al. 2019). Recently, several studies have been conducted to study the possibility of using SCMs to produce RAC. Pedro et al. (2018) examined the effect of SCMs to enhance the durability of high-performance concrete with RA. It was found that through high-quality RA and suitable mixing processes, it is possible to produce highperformance concrete replacing the totality of natural aggregates (NA) with RAs. Kurda et al. (2019) studied the effect of fly ash (FA) on water absorption and electrical resistivity of RAC. They found that water absorption increased and electrical resistivity diminished with increasing incorporation levels of RCCA, while the opposite occurred with the addition of FA for both tests. Moreover, Majhi \& Nayak (2019) have investigated the durability of RAC made with $50 \%$ RCCA and 40\% ground granulated blast furnace slag (GGBFS) and found similar durability properties of RAC with CC. Impressive conclusions were drawn by researchers who found that the addition of $10 \%$ of SF by weight of cement in RAC led to $15 \%$ to $80 \%$ less chloride ion penetration than occurred in mixes without SF (Limbachiya et al., 2012; CorralHiguera et al., 2011).

So far, various methods have been used to determine the durability of RAC. Reviewing the papers, it can be seen that the durability of RAC evaluated using water absorption, acid attack, and chloride permeability test (Thomas et al., 2013). Zhu et al. (2019) investigated the effect of recycling cycles on the durability of RAC and observed parameters such as freeze-thaw resistance and chloride ion permeability coefficient. This paper is part of a comprehensive research project undertaken by Azad University of Ahvaz (Iran) to identify the simultaneous effects of different types of RA replacement and pozzolans on mechanical, durability, and microstructure of RAC. The main objective of this paper is to evaluate the durability of RAC's made of recycled concrete coarse aggregate (RCCA) containing silica-fume (SF) and natural zeolite (NZ). One of the methods that has been less considered to determine the durability of RAC is the use of ER and its EC. Therefore, to determine the durability of RAC, in addition to the usual methods of CS, WAI, WAC, and RCPT, the amount of ER and EC are also measured and compared. Finally, the obtained results were analyzed through scanning electron microscopy (SEM).

Methodology

\section{Experimental program}

This study seeks to identify and analyze the durability performance of CC and RAC. Four levels of aggregate replacement based on the total aggregate's weight, i.e., $0 \%, 25 \%, 50 \%$, and $100 \%$ along with two different pozzolans, i.e., SF and NZ were used in this research program. The SF was replaced with 5, 10 and 15\%, and the NZ was used at three levels of 10, 20 , and $30 \%$. The mixed design was performed according to the Iranian Concrete Code (ICC, 2003) which targeted a CS of $40 \mathrm{MPa}$ over 28 days. All specimens were cast under ambient conditions and demolded at $24 \pm 2$ hours after mixing. They were then fully submerged in water at temperature $25 \pm 2{ }^{\circ} \mathrm{C}$ until the age of testing according to ASTM C192/C192M-16a. (2016) The CS test based on BS 1881- Part 116 (1983) was done at the ages of 28-day using a total of 
84 standard cubic specimens as $150 \times 150 \times 150 \mathrm{~mm}$. The durability related performance of concretes was evaluated on sets of cylindrical and disks specimens at the age of 180 days with WAI based on ASTM C 642-13 (2013), WAC based on ASTM C 1585-11 (2011), ER, EC based on ASTM C1760-12 (2012), and RCPT based on ASTM C1202-12 (2012). For a more detailed analysis and to better understand the internal structural changes of concrete, SEM was used.

\section{Materials}

\section{Binders}

The cementitious materials (CM) used in this study consisted of ordinary Portland cement (OPC), SF, and NZ. The cement used in this study was a locally produced OPC equivalent to ASTM type I-325, while NZ (clinoptilolite type) was procured from the mines of Semnan province, Iran. The total contents of $\mathrm{SiO}_{2}, \mathrm{Al}_{2} \mathrm{O}_{3}$, and $\mathrm{Fe}_{2} \mathrm{O}_{3}$ in the $\mathrm{NZ}$, and SF were found as $81 \%$ and $96.83 \%$, respectively, which are larger than the minimum requirement (70\%) specified in ASTM C 618-19 (2019) for natural pozzolans. SF was obtained from ferro-silicon alloy manufacturer in Azna, Iran. The physical properties and chemical compositions of the binders provided by the seller and presented in Table 1.

Table 1. Physical and Chemical Compositions of Cementitious Materials (\%).

\begin{tabular}{ccccccccccc}
\hline & $\mathrm{SiO}_{2}$ & $\mathrm{Fe}_{2} \mathrm{O}_{3}$ & $\mathrm{Al}_{2} \mathrm{O}_{3}$ & $\mathrm{CaO}$ & $\mathrm{MgO}$ & $\mathrm{SO}_{3}$ & $\mathrm{LOI}$ & $\begin{array}{c}\text { Specific } \\
\text { gravity } \\
\left(\mathrm{g} / \mathrm{cm}^{3}\right)\end{array}$ & $\begin{array}{c}\text { Specific } \\
\text { surface } \\
\left(\mathrm{m}^{2} / \mathrm{kg}\right)\end{array}$ & $\begin{array}{c}\text { Average } \\
\text { particle } \\
\text { size } \\
(\mu \mathrm{m})\end{array}$ \\
\hline OPC 1-325 & 21.28 & 3.7 & 6.1 & 64.34 & 2.1 & 2.13 & 2.2 & 3.15 & 295 & 26 \\
$\mathrm{NZ}$ & 68 & 1.5 & 11.5 & 2.5 & - & - & 12.2 & 2.20 & 320 & 16.8 \\
SF & 94.73 & 0.87 & 1.23 & 0.49 & 0.97 & 0.1 & - & 2.26 & 20000 & 0.15 \\
\hline
\end{tabular}

\section{Aggregates}

River sand with a maximum size (MSA) of $4.75 \mathrm{~mm}$ as fine aggregates and crushed aggregates with an MSA of $19 \mathrm{~mm}$, specific gravity of 2.57 and water absorption of $3.23 \%$ were used in the concrete mixes. The RCCA with an MSA of 19 $\mathrm{mm}$, specific gravity of 2.19 , and water absorption of $6.44 \%$ was derived from demolished concrete piles and building projects. The demolished material was collected from the site and crushed in the laboratory by a jaw crusher (Figure 1). The properties and age of parent concrete of RCCA were unknown. Based on the heat treatment method proposed by de Juan and Gutiérrez (2009), the attached mortar was approximately 55\% and 60\% for RCA with MSA of 19 mm and $9.5 \mathrm{~mm}$, respectively. The natural fine and RCCA's grading and their combination are shown in Figures 2-4, along with the upper and lower ICC limitations. To compare and better understand the limitations of ICC, the aggregates grading limitations of ASTM C33 are presented in the Figures 2 and 3.

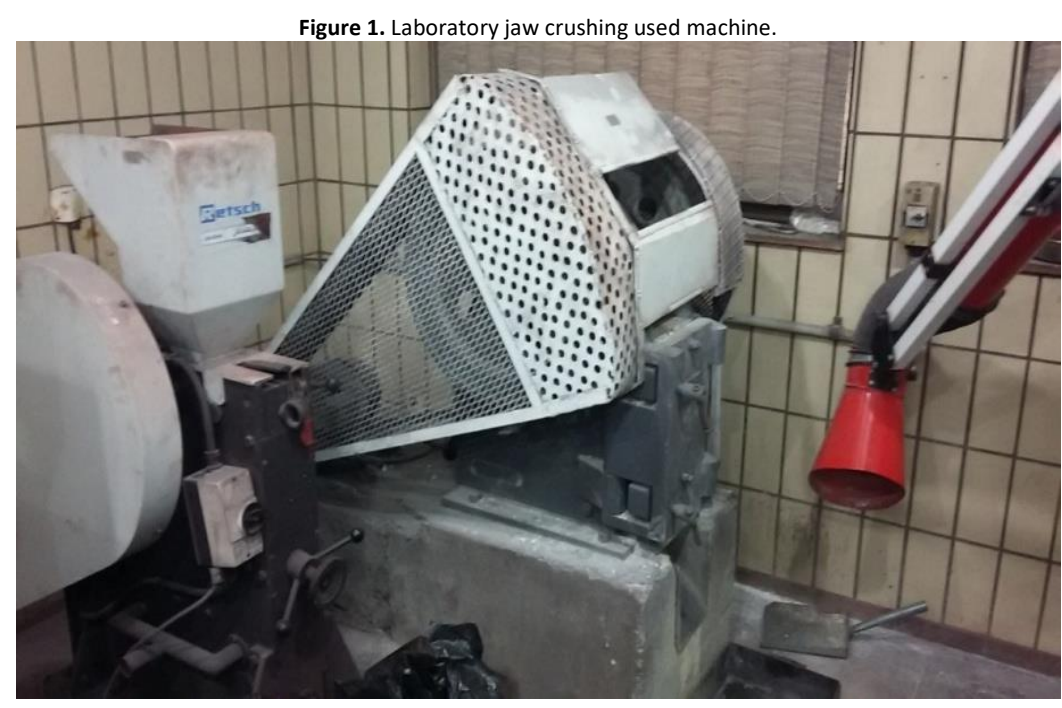


Figure 2. RCCA particles' grading with respect to ICC and ASTM C33 limitations.

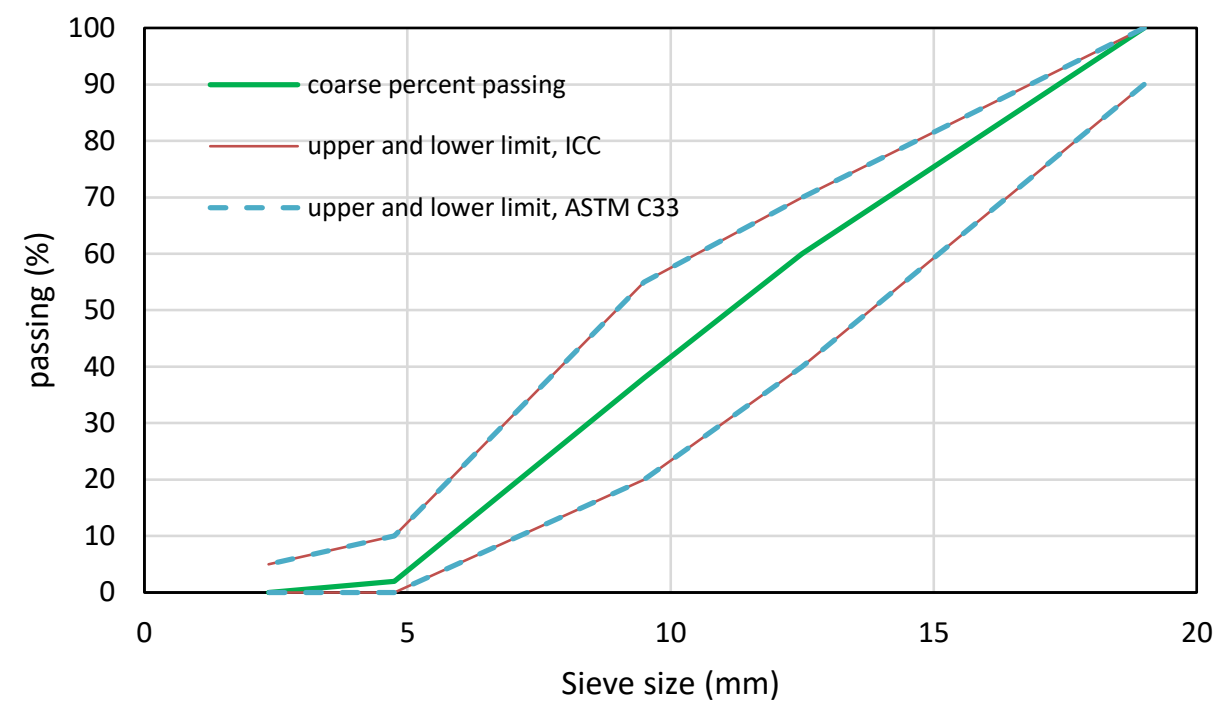

Figure 3. Natural fine particles' grading with respect to ICC and ASTM C33 limitations.

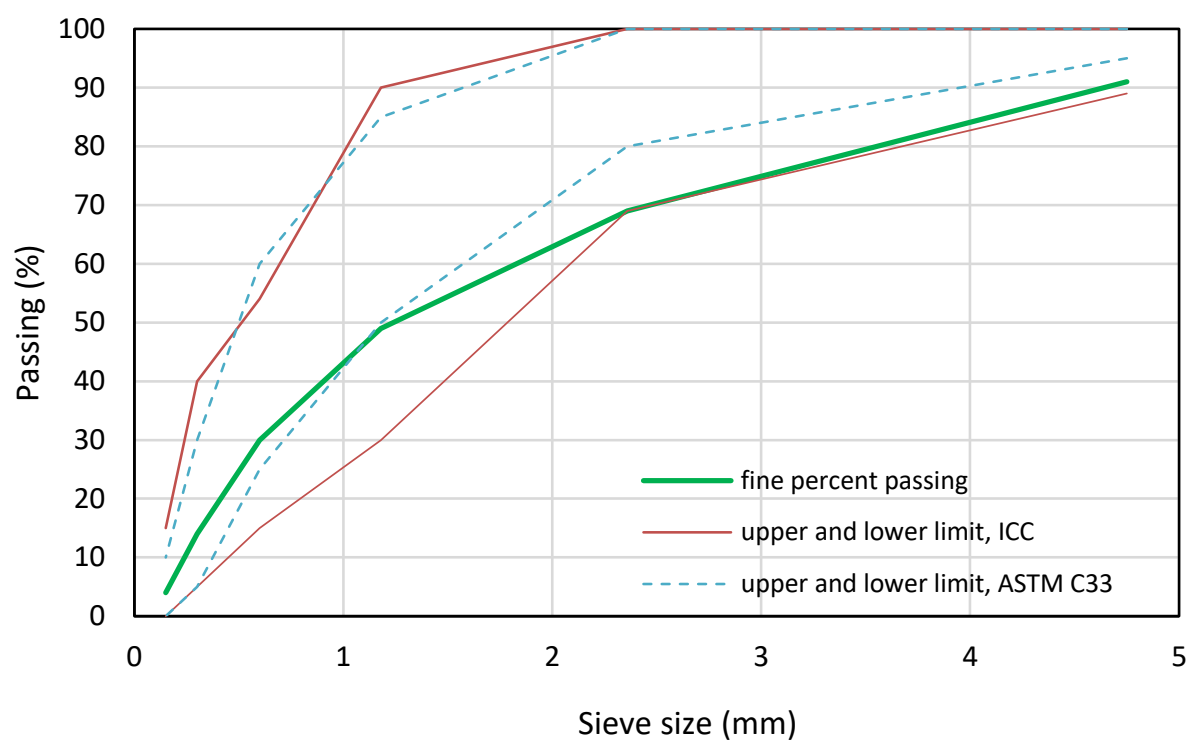

Figure 4. Natural fine and RCCA combination particles' grading based on ICC.

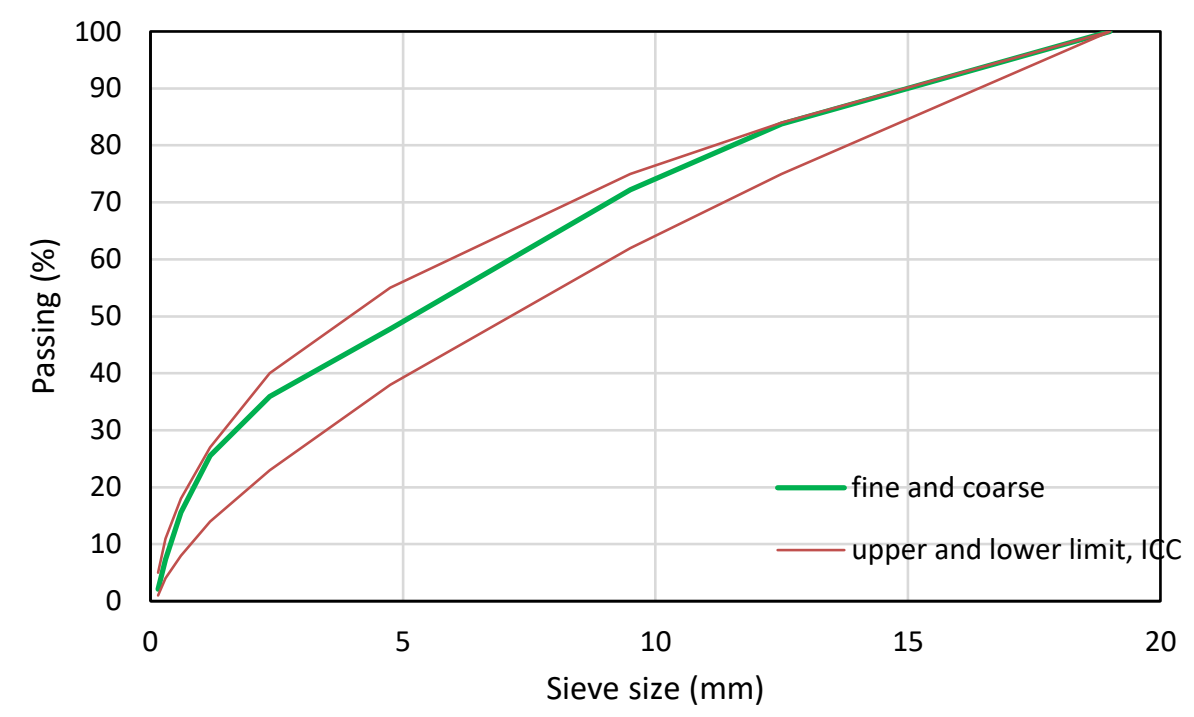




\section{Super-plasticizer}

To obtain proper workability, a poly carboxyl-based super-plasticizer (SP) with density $1.1 \pm 0.02 \mathrm{~g} . \mathrm{cm}^{3}$ was used. The maximum use of $1 \%$ weight of $\mathrm{CM}$ revealed the required workability.

\section{Mixing process}

Two concrete mixes were produced, CC and RAC. The CC mix was prepared with $100 \%$ natural aggregates while the RAC mixes were prepared with 3 levels of 25\%,50\%, and 100\% RCCA replacement. All mixes were made with a constant W.B ratio as 0.36 and $420 \mathrm{~kg} \cdot \mathrm{m}^{3} \mathrm{CM}$ content. The mixes were developed in a $150 \mathrm{~L}$ laboratory mixer based on the following method called three stage mixing method (TSMM) (Jalilifar et al., 2016). First, all of the coarse aggregates, 1.3 by weight of water and 1.2 by weight of pozzolanic material were mixed for 1 minute. Based on the two-stage mixing method (TSMA) (Tam et al. 2005), the primary objective of this method was to ensure complete penetration of pozzolanic slurry in the voids of RCCA and filling them, as well as to produce a thin layer of CM on attached mortar to improve adhesion of old and new mortars (Figure 5). Secondly, 1.2 by weight of natural sand, 1.2 by weight of cement, and 1.3 by weight of water were mixed for 2 min. Lastly, the remaining materials ( 1.2 by weight of cement, 1.2 by weight of natural sand, 1.2 by weight of pozzolanic material, and 1.3 by weight of water) were added and mixed for 6 min. Details are reported in Table 2.

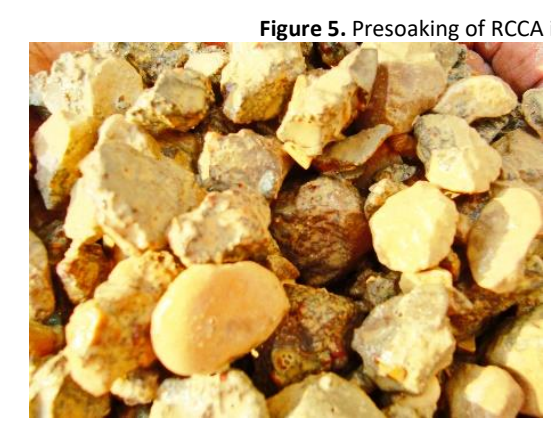

(a)

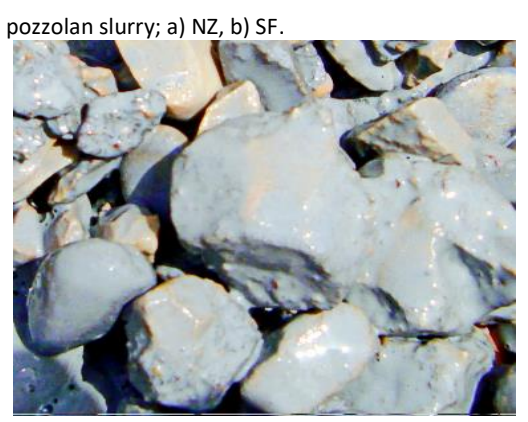

(b)

\begin{tabular}{ccccccc}
\multicolumn{7}{c}{ Table 2. Mix Proportions of CC and RAC without pozzolans. } \\
\hline Notation & $\begin{array}{c}\text { CM } \\
(\mathrm{kg})\end{array}$ & $\begin{array}{c}\text { RCCA } \\
(\mathrm{kg})\end{array}$ & $\begin{array}{c}\text { NCA } \\
(\mathrm{kg})\end{array}$ & $\begin{array}{c}\text { Sand } \\
(\mathrm{kg})\end{array}$ & $\begin{array}{c}\text { W } \\
(\mathrm{kg})\end{array}$ & $\begin{array}{c}\text { SP } \\
(\text { liter })\end{array}$ \\
\hline CC & 420 & - & 815 & 888 & 150 & 4.2 \\
RC25 & 420 & 204 & 611 & & & \\
RC50 & 420 & 407.5 & 407.5 & & & \\
RC100 & 420 & 815 & - & & & \\
\hline
\end{tabular}

Results and Discussion

\section{Compressive strength}

The average results of the 28-day CS of concretes are shown in Table 3 and Fig. 6 . The 28-day CS on CC was found as 44.2 MPa while no impressive CS change was found on RC25. Meanwhile, the obtained results revealed around $14 \%$ and $18 \%$ reduction in 28-day CS of RC50 and RC100 compared with that of CC, respectively. Based on Fig. 6 , it can be concluded that, due to the increment of the amount and size of porosities with elevation of the level of RCA replacement in concretes without pozzolans, the CS of concretes significantly dropped.

The CS reduction of RC100 compared to that of CC can be attributed to two main reasons. Firstly, since the water absorption of RCCA is larger than that of NCA, a large amount of water will be absorbed by RCCA, which will reduce the W.C ratio causing incomplete hydration of cement (Zhu et al., 2018). Secondly, the lower strength and higher porosity of RCCA will cause stress concentration when being subjected to axial pressure and will have a negative effect on the 
CS of RAC. Etxeberria et al. (2007) and Hanson (1992) found 20\%-30\%, while Zhu et al. (2018) achieved a 66\% strength reduction for full scale RAC. However, Kanellopoulos et al. (2014) and Younis and Pilakoutas (2013) concluded that the CS of RAC was close or even higher than that of NAC. For concretes containing SF, the proper CS gain was found for $10 \%$ of SF, where the RC100-SF10 reached $17 \%$ CS higher than that of CC. This can be associated with the pre-saturation of the RCCA in SF slurry. The reason is that the SF slurry reduced porosity at the RCCA surface and caused the ITZ to have a more effective pozzolanic reaction (Tam et al., 2005). It is known that SF accelerates hydration reactions in Portland cement by providing nucleation sites for $\mathrm{C}-\mathrm{H}$ within minutes after reaction commences, and also by reacting with $\mathrm{Ca}{ }^{++}$ ions. Reduced $\mathrm{Ca}^{++}$ion affects the nature of hydration products (Cheng-Yi and Feldman, 1985). Mehta and Monteiro (2006) have identified two physical effects for the reaction between pozzolanic materials and $\mathrm{C}-\mathrm{H}$ as pore size modification and grain size modification. Both processes ultimately lead to increased strength of cement paste. In other words, additional C-S-H gel produced due to the reaction of SF and C-H reduces the volume of voids in the cement paste and thus increases the density of the cement paste. Therefore, it is expected to observe higher CS in concretes containing SF.

As can be seen, compared to the similar RAC without pozzolan, at higher RCCA replacement, more proper effect of SF $10 \%$ application was found. In this regard, compared to RC25, the CS improvement of RC25-SF10 was found 34\%, while, the CS of RC100-SF10 was found 43\%, compared to RC100. This implies the more favorable effect of SF on the CS improvement at higher RCCA replacement. The results also indicated that, in addition to the concretes containing $10 \%$ of SF, the use of $15 \%$ of SF led to a higher 28 -day CS of RC25 than that of CC.

The results of Table 3 indicate that the CS of CC and RAC containing NZ were lower than that of CC and RAC without pozzolan. The use of $10 \%$ of $\mathrm{NZ}$ as the optimum level of $\mathrm{NZ}$ replacement for RC25 showed about $10.4 \%$ CS reduction in comparison to CC and reached $39.6 \mathrm{MPa}$. The considerable effect of the use of NZ indicated that the addition of $10 \%$ of NZ had a negligible effect on CS decrement, where in comparison to CC-NZ10, a 3\% CS drop was recorded for RC100NZ10. Furthermore, compared to RC100, the unchanged CS of RC100-NZ10 suggests that the use of $10 \%$ of NZ causes this pozzolan to be a better CM replacement as compared to strength material improvement. In comparison to the concretes containing $10 \%$ of NZ, lower CS results of the concretes containing $20 \%$ and $30 \%$ of NZ were recorded. This implies that due to the lower pozzolanic action of NZ and cement hydration products, the use of NZ beyond $10 \%$ causes a significant reduction in CS. From the point of view of mechanical properties, the loose in CS of concretes containing NZ compared to concretes containing SF can be explained by the amount of pozzolanic reactivity and particle size of NZ. Depending on the type and classification of NZ, its pozzolanic reactivity varies. However, the results of thermogravimetric experiments on NZ and SF samples showed that even the high purity type of NZ has less pozzolanic reactivity compared to SF (Ahmadi and Shekarchi, 2010). Therefore, it is obvious that compared to RAC containing SF, more amounts of $\mathrm{C}-\mathrm{H}$ remain during the hydration process in RAC containing NZ. Therefore, concretes containing NZ will have a weaker structure. In addition, due to the larger particle size of NZ $(16.8 \mu \mathrm{m})$ compared to SF $(0.15 \mu \mathrm{m})$, it is predictable that the cement matrix containing NZ have more porosity and more heterogeneity.

Table 3. 28- day CS \pm standard deviation and relative differences to CC (MPa).

\begin{tabular}{|c|c|c|c|c|c|c|c|c|c|c|c|c|}
\hline \multirow[b]{3}{*}{ Notation } & \multicolumn{12}{|c|}{ Aggregates replacement ratio (\%) } \\
\hline & \multicolumn{3}{|c|}{0} & \multicolumn{3}{|c|}{25} & \multicolumn{3}{|c|}{50} & \multicolumn{3}{|c|}{100} \\
\hline & fc & SD & $\Delta \%$ & fc & SD & $\Delta \%$ & fc & SD & $\Delta \%$ & fc & SD & $\Delta \%$ \\
\hline $\mathrm{RC}$ & 44.2 & 3.8 & - & 44 & 2.0 & -0.5 & 38.1 & 1.5 & -13.8 & 36.4 & 3.8 & -17.6 \\
\hline SF5 & 50.1 & 2.0 & 13.3 & 43.4 & 1.5 & -1.8 & 42.8 & 2.1 & -3.2 & 39.3 & 1.9 & -11.1 \\
\hline SF10 & 57.4 & 2.5 & 29.9 & 53.8 & 2.6 & 21.7 & 52 & 2.8 & 17.6 & 51.7 & 3.5 & 17.0 \\
\hline SF15 & 47.2 & 1.3 & 6.8 & 45.4 & 2.5 & 2.7 & 41 & 1.3 & -7.2 & 40.7 & 2.6 & -7.9 \\
\hline NZ10 & 37.4 & 1.3 & -15.4 & 39.6 & 2.4 & -10.4 & 38.7 & 2.3 & -12.4 & 36.3 & 1.7 & -17.9 \\
\hline NZ20 & 34.8 & 2.6 & -21.3 & 37.2 & 1.2 & -15.8 & 31.3 & 2.4 & -29.2 & 32.4 & 1.8 & -26.7 \\
\hline NZ30 & 37.4 & 1.9 & -15.4 & 31.3 & 2.4 & -29.2 & 29.2 & 1.7 & -33.9 & 23.7 & 3.7 & -46.4 \\
\hline
\end{tabular}




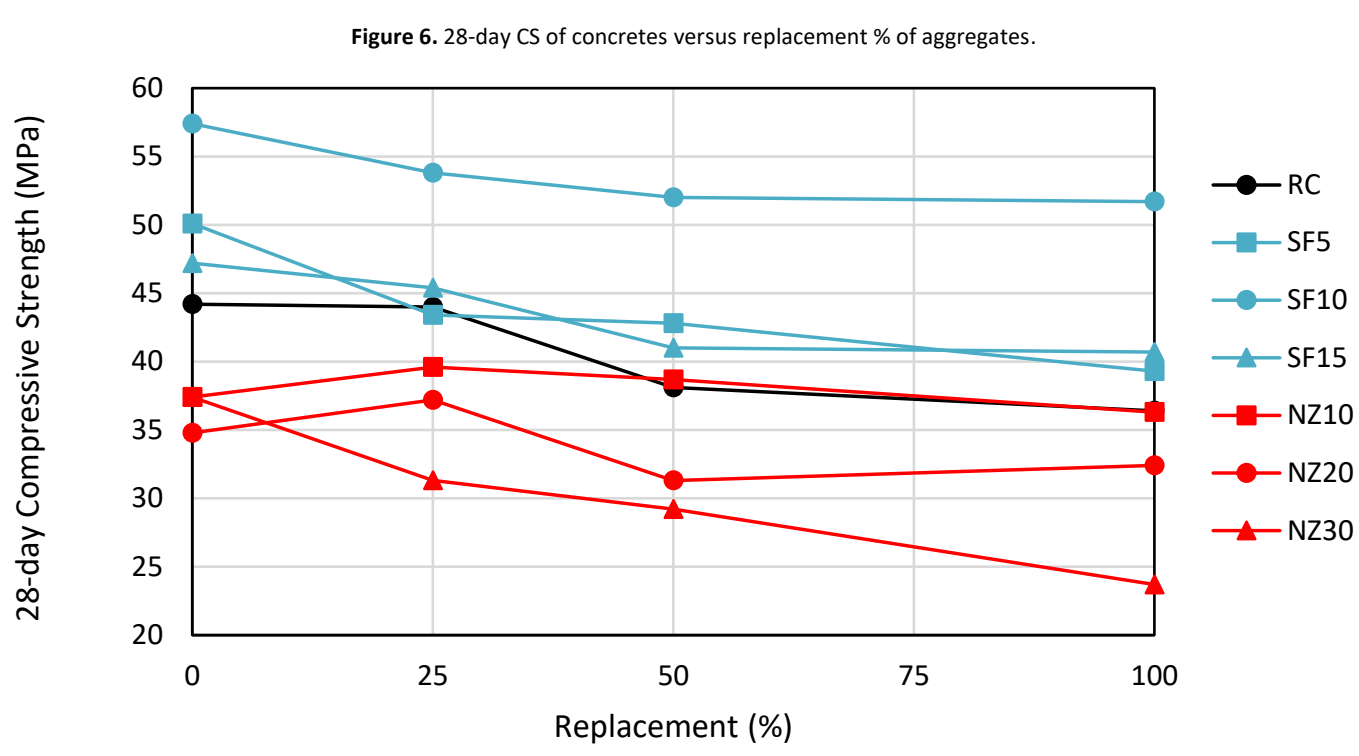

Water Absorption by Immersion (WAI)

Table 4 and Fig. 7 present the WAI values obtained for the CC and RAC, with and without pozzolans. As can be seen, there is a linear increase of the WAI with the rise of RCCA replacement. The correlation coefficient of graphs for different WAs by immersion between 0.91 for concretes containing $15 \%$ of SF and 0.99 for concretes containing $30 \%$ NZ could describe this linear behavior. The WAI of CC was obtained as $4.92 \%$ and a negligible and $87 \%$ increment on WAI were reported for RC25 and RC100, respectively. Pedro et al. (2018) and Matias et al. (2013) explained this WAI increment based on the incorporation of RCCA, which possesses a more porous structure, due to the presence of adhered mortar. On the other hand, Kwan et al. (2012) believed that, due to the increment of RCCA replacement, more osmosis pressure has been created in the concrete, causing more WAI of concrete. Furthermore, due to the higher attached mortar volume of full-scale replacement of RCCA, the air content of RAC increased and led to higher WAI. The obtained results have a good correlation with Fonteboa et al. (2018) findings where they have shown a 70\% increment on WAI for RC100. Meanwhile, Rea et al. (2019) based on RA type, found a maximum 33\% increment on WAI. Note that, due to the several factors, i.e., RCA type, quality, moisture, and crushing stages, the researchers have obtained different results on WAI. In this regard, compared to CC, statistical analysis showed a 2.47-fold increase in WAI for RC100 (Silva, 2015).

Table 4. 180-day WAl \pm standard deviation and relative differences to N.P (0) (\%).

\begin{tabular}{|c|c|c|c|c|c|c|c|c|c|c|c|c|}
\hline & \multicolumn{12}{|c|}{ Aggregates replacement ratio (\%) } \\
\hline & \multicolumn{3}{|c|}{0} & \multicolumn{3}{|c|}{25} & \multicolumn{3}{|c|}{50} & \multicolumn{3}{|c|}{100} \\
\hline & WAI & SD & $\Delta \%$ & WAI & SD & $\Delta \%$ & WAI & SD & $\Delta \%$ & WAI & SD & $\Delta \%$ \\
\hline N.P & 4.92 & 0.27 & 0.0 & 4.96 & 0.29 & 0.8 & 6.83 & 0.07 & 38.8 & 9.2 & 0.11 & 87.0 \\
\hline SF5 & 4.23 & 0.18 & -14.0 & 5.03 & 0.08 & 2.2 & 6.58 & 0.19 & 33.7 & 7.96 & 0.18 & 61.8 \\
\hline SF10 & 3.86 & 0.21 & -21.5 & 4.03 & 0.29 & -18.1 & 5.12 & 0.17 & 4.1 & 7.03 & 0.17 & 42.9 \\
\hline SF15 & 4.11 & 0.14 & -16.5 & 5.11 & 0.12 & 3.9 & 7.56 & 0.18 & 53.7 & 8.6 & 0.08 & 74.8 \\
\hline NZ10 & 4.37 & 0.11 & -11.2 & 4.96 & 0.16 & 0.8 & 7.01 & 0.39 & 42.5 & 8.56 & 0.15 & 74.0 \\
\hline NZ20 & 4.92 & 0.13 & 0.0 & 5.23 & 0.08 & 6.3 & 6.56 & 0.23 & 33.3 & 8.79 & 0.26 & 78.7 \\
\hline NZ30 & 5.98 & 0.21 & 21.5 & 7.11 & 0.21 & 44.5 & 8.45 & 0.26 & 71.7 & 10.71 & 0.34 & 117.7 \\
\hline
\end{tabular}

Analyzing Fig. 7, it can be seen that compared to CC, the use of $10 \%$ of SF can lower and enhance the WAI of RC25 and RC100 up to $18 \%$ and $43 \%$, respectively. However, the use of $10 \%$ of NZ showed a negligible change on WAI and $74 \%$ increment for RC100. In comparison to RAC without pozzolan, the use of $10 \%$ and $20 \%$ of NZ revealed no considerable change on WAI. As an explanation, the unchanged WAI of RAC containing $10 \%$ and $20 \%$ of NZ suggests that this pozzolan could play the role of alternative cementitious materials which showed a lower effect in improving durability performance of RAC. The SEM tests confirmed these findings where the internal structure of ITZ of RC100-SF10 was relatively compacted and denser with fewer pores seen in Fig. 8. Meanwhile, Fig. 9 displays that in comparison to $10 \%$ of SF, the use of $10 \%$ of NZ led to production of a smaller volume of hydration products. Also, based on morphological 
view, more discontinuous textures with many pores and discontinuity were seen in the internal structure of RC100NZ10. Fig. 10 displays internal structure of RC100-Z10 and shows that hydration products failed to bridge the gap between the pores and S-C-H. As can be seen, RAC containing NZ have higher WAI than RAC containing SF and CC. Also, increasing the amount of NZ replacement has increased the amount of WAl in different types of RAC. In fact, the answer to this phenomenon can be considered in the nature of NZ. Due to their porous structure, NZ particles have a large volume of voids, so the ability to water absorption of unreacted NZ particles, causes RAC containing NZ to absorb more water than RAC containing SF and CC. According to the Table 1, the porous structure of NZ particles can be seen where in comparison with cement particles LOI (2.2), the LOI of NZ is recorded 12.2 .

Figure 7. 180-day WAI of concretes.
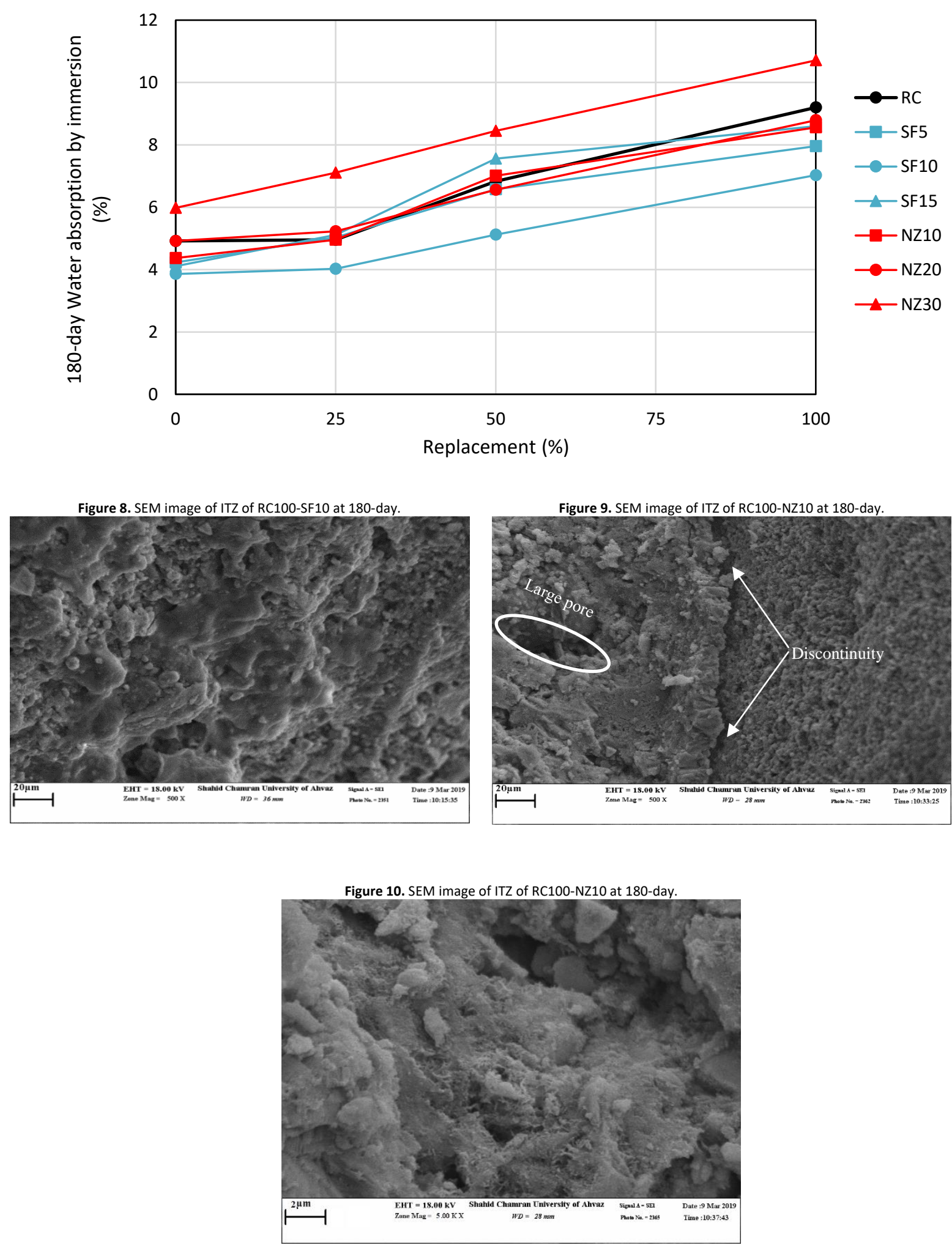


\section{Water Absorption by Capillarity (WAC)}

Table 5 and Fig. 11 exhibit the WAC test of CC and RAC with and without pozzolans. The WAC of CC was recorded as $4.92 \mathrm{~mm}$ after $72 \mathrm{~h}$, while compared to $\mathrm{CC}$, the use of all types and dosages of pozzolans led to diminish WA by capillarity of CC containing pozzolans. A 25\% replacement of RCCA indicated a negligible increment while full replacement of RCCA showed a 91\% increment on WAC. This is associated with the increase in the size and volume of capillary pores due to the increase in the volume of attached mortar at higher RCCA replacements. The best performance of pozzolanic materials was seen at $10 \%$ of SF, where compared to CC, a $27 \%$ reduction and $57 \%$ increment of WAC were reported for CC-SF10 and RC100-SF10, respectively. In comparison to RC100, the use of $10 \%$ of SF revealed $18 \%$ fall of WAC for RC100-SF10. The obtained results were confirmed under the examination of SEM tests as presented in Fig. 8 and Figs. 12-13. Figs. 12-13 illustrates a looser and less compacted cement paste and more discontinuity along with a large number of voids in ITZ of RC100. The size of macro voids reached beyond 125 microns, and a large number of micropores distributed between hydration products caused a decline in ITZ density. The above-mentioned factors elevate the amount of WAC of RC100. Meanwhile, the pozzolanic reaction between $\mathrm{C}-\mathrm{H}$ and SF caused a denser and compacted cement paste and ITZ for RC100-SF10, and reduced the capillary pores and eventually improved the density of paste and ITZ (Fig. 8).

In the RAC containing $10 \%$ and $20 \%$ of NZ, up to $25 \%$ replacement of RCCA showed less WAC compared to CC. However, in comparison to CC, the use of $10 \%$ of NZ as an optimum level of replacement of this pozzolan showed a $62 \%$ decrement of WAC. Compared to SEM image of RC100-SF10 (Fig. 8), Fig. 9 displays higher amounts of porosity and larger voids as well as discontinuity between hydration products. It is obvious that due to the increase in the number of pores and the development of the interconnected space between them, the WAC of RAC containing the NZ will be further enhanced. Fig. 14 indicates that by increasing the NZ replacement from $10 \%$ to $20 \%$, the capillary space between C-S-H gels was expanded more widely. So, the larger amount of WAC of RC100-NZ20 was reasonable. Another reason for the better WAC results of concretes containing SF compared to concretes containing NZ can be related to the particle size of these two pozzolans. Because the finer SF particles size cause the voids and discontinuous spaces inside the concrete to be filled by unreacted SF particles. Therefore, the finer the particles size, the smaller the capillary and the higher the density of the concrete.

Table 6 shows the capillary absorption coefficient (S) of CC and RAC with and without pozzolans. The following equation, which states that the capillary absorption (Wc) is proportional to the square root of time (t), was proposed by Hall (1989).

$\mathrm{Wc}=\mathrm{S} \mathrm{Vt}$

Based on Table 7 suggested by Browne (1991), to assess the quality of concrete according to their capillary absorption coefficient, all of the fully replaced RAC with and without pozzolans, RC50, RC50-SF15, RC50-NZ20, and RC50-NZ30 were classified as average. On the other hand, all CC and RC25 cases with and without pozzolans were classified as high quality concretes.

\begin{tabular}{|c|c|c|c|c|c|c|c|c|c|c|c|c|}
\hline & \multicolumn{12}{|c|}{ Aggregates replacement ratio (\%) } \\
\hline & \multicolumn{3}{|c|}{0} & \multicolumn{3}{|c|}{25} & \multicolumn{3}{|c|}{50} & \multicolumn{3}{|c|}{100} \\
\hline & CWA & SD & $\Delta \%$ & CWA & SD & $\Delta \%$ & CWA & SD & $\Delta \%$ & CWA & SD & $\Delta \%$ \\
\hline N.P & 4.92 & 0.10 & 0.0 & 5.01 & 0.17 & 1.8 & 7.59 & 0.08 & 54.3 & 9.38 & 0.05 & 90.7 \\
\hline SF5 & 4.18 & 0.17 & -15.0 & 5.03 & 0.14 & 2.2 & 6.13 & 0.23 & 24.6 & 8.37 & 0.13 & 70.1 \\
\hline SF10 & 3.58 & 0.08 & -27.2 & 4.09 & 0.29 & -16.9 & 5.88 & 0.27 & 19.5 & 7.7 & 0.13 & 56.5 \\
\hline SF15 & 4.23 & 0.11 & -14.0 & 5.78 & 0.14 & 17.5 & 7.82 & 0.06 & 58.9 & 9.52 & 0.23 & 93.5 \\
\hline NZ10 & 4.12 & 0.08 & -16.3 & 4.71 & 0.06 & -4.3 & 5.89 & 0.08 & 19.7 & 7.95 & 0.36 & 61.6 \\
\hline NZ20 & 4.18 & 0.07 & -15.0 & 4.71 & 0.11 & -4.3 & 6.92 & 0.16 & 40.7 & 8.25 & 0.21 & 67.7 \\
\hline NZ30 & 4.42 & 0.18 & -10.2 & 5.36 & 0.11 & 8.9 & 7 & 0.13 & 42.3 & 8.85 & 0.35 & 79.9 \\
\hline
\end{tabular}


Figure 11. 180-day WAC of concretes

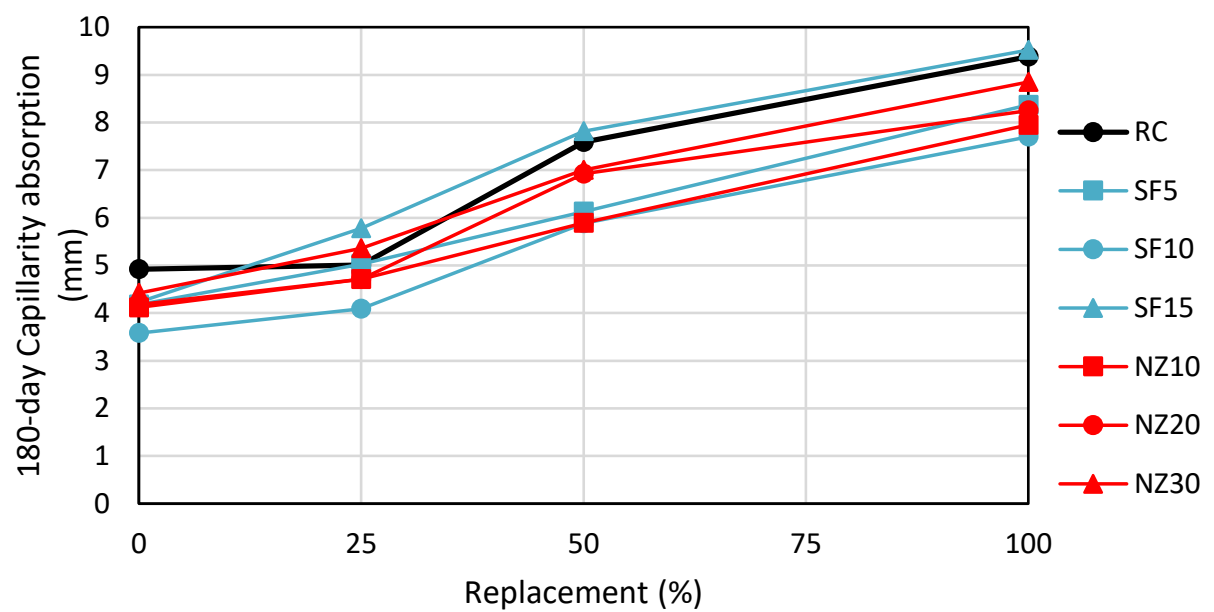

Figure 12. SEM image of ITZ of RC100 at 180-day

Figure 13. SEM image of ITZ of RC100 at 180-day
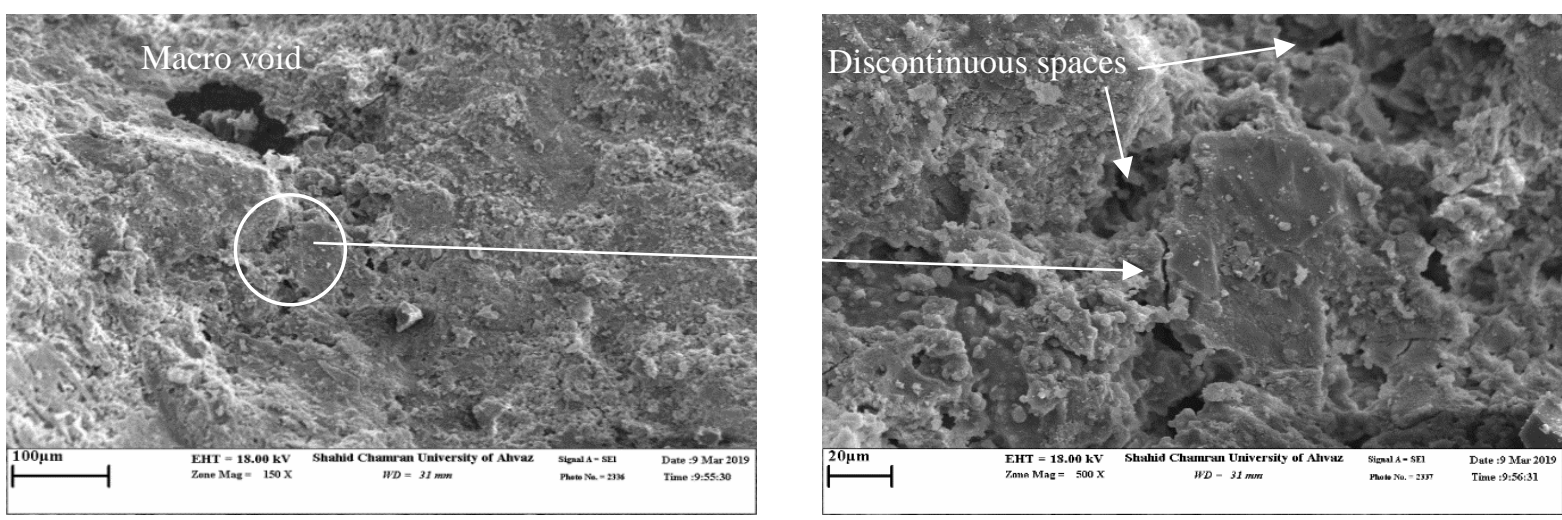

Figure 14. SEM image of ITZ of RC100-NZ20 at 180-day

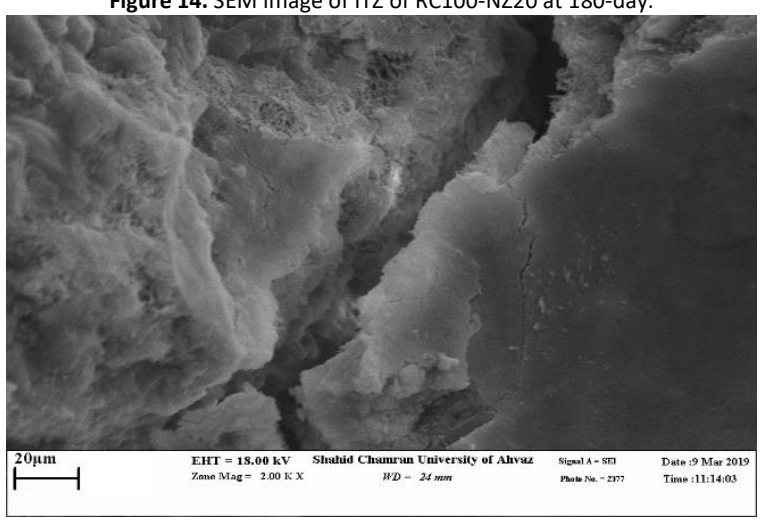

Table 6. 180-day capillary absorption coefficient ( (mg.mm². $\left.\left.\mathrm{min}^{0.5}\right)\right)$

\begin{tabular}{ccccc}
\hline & \multicolumn{4}{c}{ Aggregates replacement ratio (\%) } \\
\cline { 2 - 5 } RC & 0 & 25 & 50 & 100 \\
\cline { 2 - 5 } SF5 & 0.075 & 0.076 & 0.115 & 0.143 \\
SF10 & 0.064 & 0.077 & 0.093 & 0.127 \\
SF15 & 0.054 & 0.062 & 0.089 & 0.117 \\
NZ10 & 0.064 & 0.088 & 0.119 & 0.145 \\
NZ20 & 0.063 & 0.072 & 0.09 & 0.121 \\
NZ30 & 0.064 & 0.072 & 0.105 & 0.126 \\
\hline
\end{tabular}


Table 7. Classes of concrete quality based on their capillary coefficient presented with Browne (1991).

\begin{tabular}{cc}
\hline $\begin{array}{c}\text { Capillary absorption coefficient } \\
\left(\mathrm{mg} \cdot \mathrm{mm}^{2} \cdot \mathrm{min}^{0.5}\right)\end{array}$ & Quality class \\
\hline $\mathrm{S}>0.2$ & Reduced \\
$0.1<\mathrm{S}<0.2$ & Average \\
$\mathrm{S}<0.1$ & High \\
\hline
\end{tabular}

Figure 15 displays the correlation between 180-day WAC and 180-day WA by capillary of concretes. It can be seen that there is an appropriate linear relationship between WAI and WAC of concretes with a relatively good coefficient of determination (0.83).

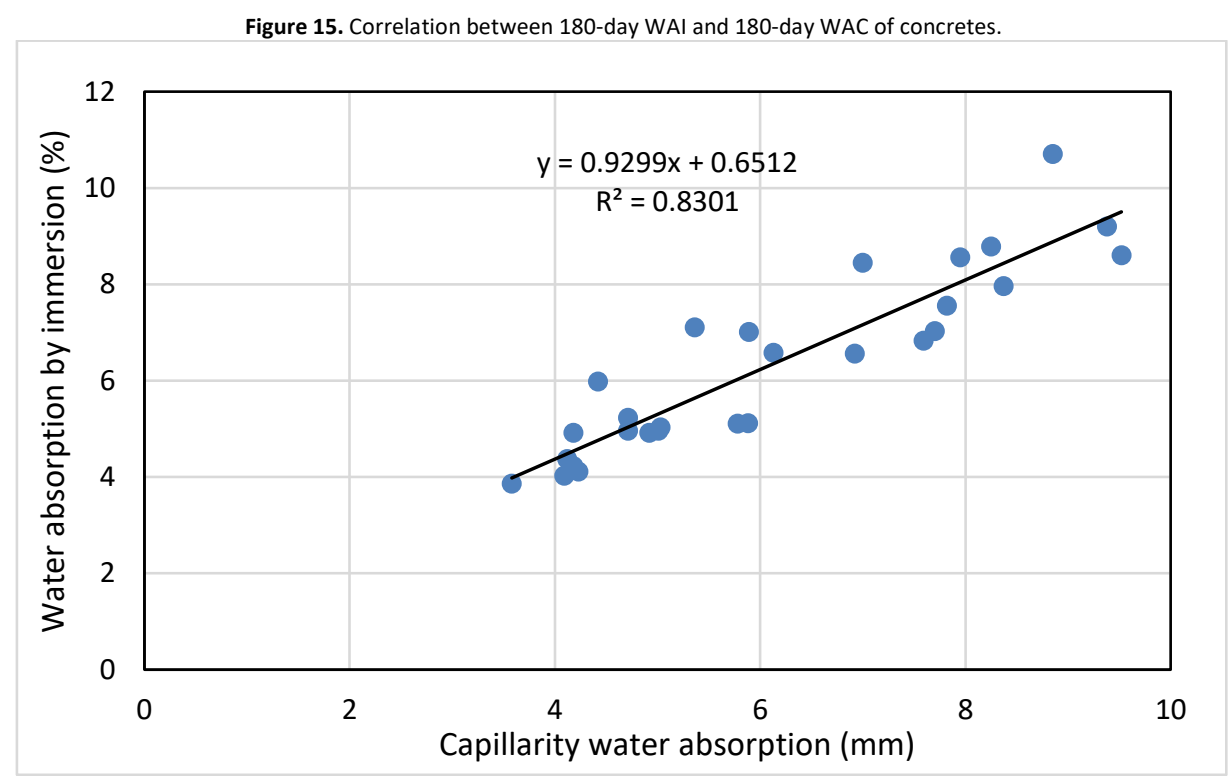

\section{Electrical Resistivity (ER)}

Based on the ER of concrete, Malhorta and Carino (2003) classified the risk of corrosion in three broad types: ER> 120, $50<E R<120$, and $E R<50 \Omega . m$ for which the risk of corrosion of the reinforcement is impossible, moderate and imperative, respectively. The results are presented in Table 8 and Fig. 16. Similar to the Kurda et al. (2019) findings, the ER of concretes without pozzolans decreased with RCCA rise. Although the RC25 reached the same ER as with CC, a 31\% reduction was recorded for ER of RC50. The results revealed a moderate risk of corrosion up to $50 \%$ replacement of RCCA and imperative risk for fully replaced RCCA concrete. Contrary to the current research, Kurda et al. (2019) found a moderate risk of corrosion for RC100 during 90 to 365 days. The general idea of ER decrement of RC100 was related to the higher water absorption and porosity of RCCA compared to NCA. However, the effect of pozzolanic materials can be seen where, compared to the RC100 (imperative risk of corrosion), all full-scale RAC containing pozzolans were placed in the moderate risk of corrosion. As the results show, the average ER of RAC containing SF and NZ at each specific RCCA replacement level are close to each other. It seems that the effect of the chemical changes caused by these two pozzolans is close to each other.

Based on the proposed category, only a RC25-SF10 was classified as a concrete with an impossible risk of corrosion. On the other hand, the results of RC25-SF15 and RC25-Z10 were too close to the impossible risk of corrosion range. Based on the results obtained from WAI and WAC tests, it was predicted that RC100-Z10 and RC100-Z20 had less ER compared to RC100-SF10. However, the results showed that this hypothesis was not true. The authors believed that although the use of pozzolans cause an increment in hydration products and lead to a lower capillarity and discontinuity in internal structure of concretes, the ER results were influenced by internal chemical and pore solution changes rather than the porosity of concrete. In support of this theory, Naiqian and Tingyu (1998) also believe that NZ seems to reduce the ionic concentration of concrete and increase the ER of concrete. 
Table 8. 180-day Specific ER \pm standard deviation and relative differences to $\mathrm{CC}(\mathrm{k} \Omega-\mathrm{cm})$.

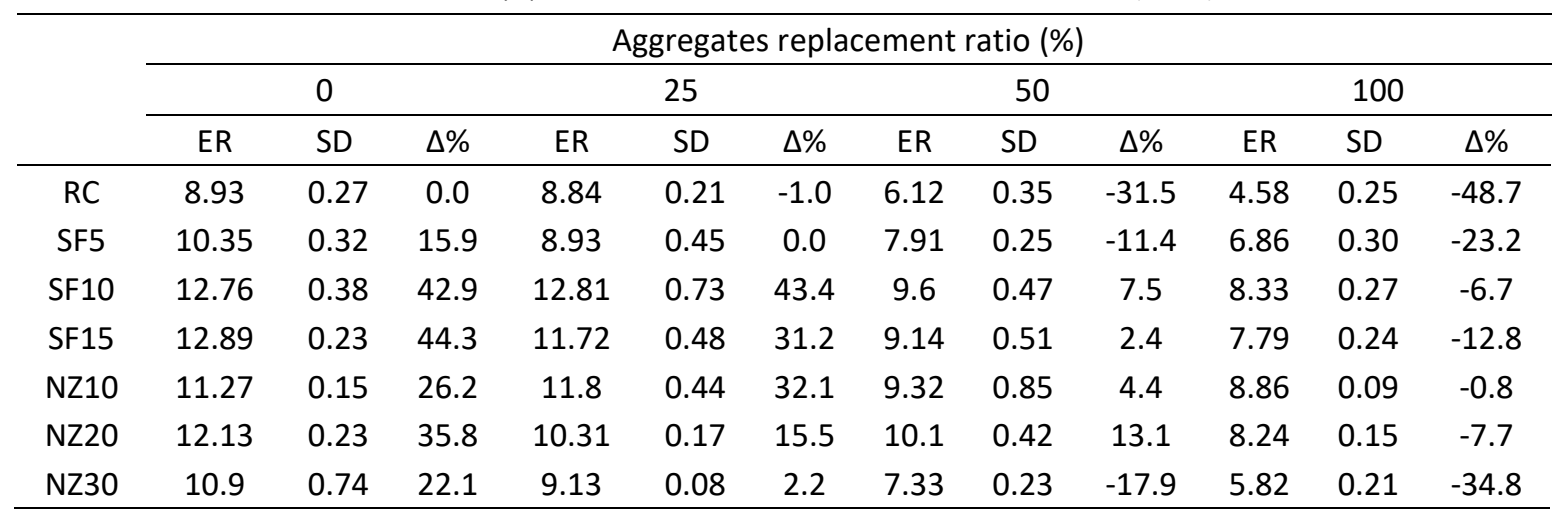

Figure 16. 180-day electrical resistance of concretes.

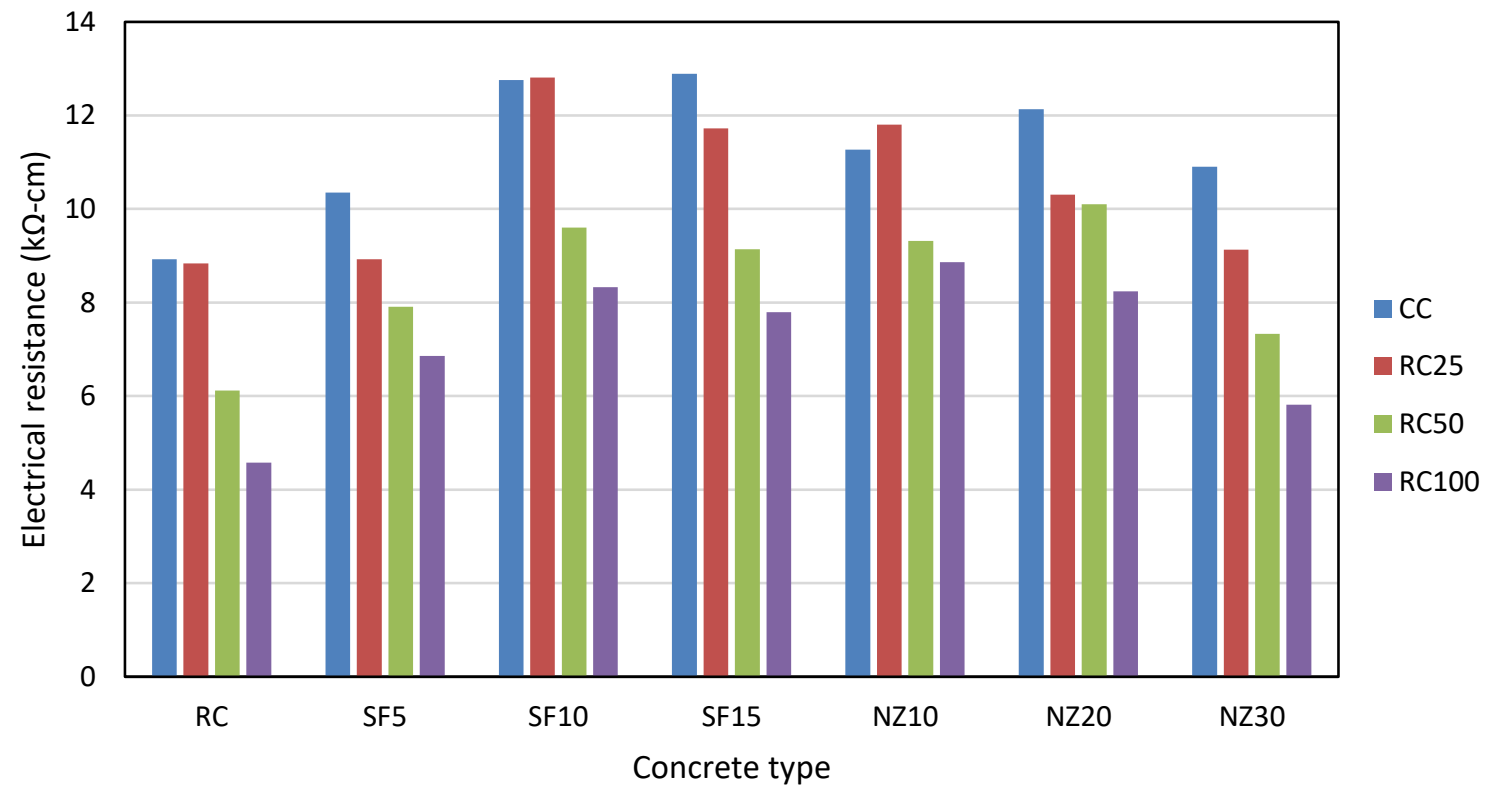

\section{Electrical Conductivity (EC)}

This test is used to determine the resistance of concrete to rapid chloride ion penetration of saturated specimens. The test was conducted based on ASTM C1760 (2012). In Table 9 and Fig. 17, the values of EC of concretes are presented. The results showed that the RC25 passed electrical current $17 \%$ more than CC did, and full replacement of RCCA caused a $67 \%$ increment of EC. The proper effect of the use of SF was seen; in comparison to CC, the use of $10 \%$ and $15 \%$ of SF caused a $38 \%$ reduction of EC.

In general, the increase in EC was seen with RCCA replacement elevation. However, note that for concretes containing pozzolans, the rate of EC increment was reduced with RCCA growth. The lower EC losses of concrete containing pozzolans with the rise in the incorporation of RCCA can be attributed to the decline of pores, cracks and discontinuity of the internal structure of concretes. The higher pozzolanic reactivity of SF and NZ led to the higher compacted concrete, lower capillary pores, and longer capillary path. Unexpectedly, the obtained EC test results were not completely in line with the ER test results. The RC100 containing various dosages of SF attained lower EC than CC did. Thus, comparing the EC test results with ER and WAI and WAC, it can be concluded that, due to the pozzolanic reactions, the EC was more affected by the internal chemical changes and chemical pore solution changes rather than by the size and amount of pores. Similar findings with less intensity were observed for concretes containing $10 \%$ of NZ. On the other hand, the results showed that the higher dosages of NZ replacement caused higher EC. 
Table 9. 180-day EC \pm standard deviation and relative differences to CC (mS.m).

\begin{tabular}{|c|c|c|c|c|c|c|c|c|c|c|c|c|}
\hline & \multicolumn{12}{|c|}{ Aggregates replacement ratio (\%) } \\
\hline & \multicolumn{3}{|c|}{0} & \multicolumn{3}{|c|}{25} & \multicolumn{3}{|c|}{50} & \multicolumn{3}{|c|}{100} \\
\hline & $\mathrm{EC}$ & SD & $\Delta \%$ & EC & SD & $\Delta \%$ & EC & SD & $\Delta \%$ & EC & SD & $\Delta \%$ \\
\hline $\mathrm{RC}$ & 15.90 & 0.23 & 0.0 & 18.60 & 0.29 & 17.0 & 21.90 & 0.23 & 37.7 & 26.50 & 0.39 & 66.7 \\
\hline SF5 & 12.60 & 0.29 & -20.8 & 12.65 & 0.46 & -20.4 & 14.00 & 0.25 & -11.9 & 16.30 & 0.20 & 2.5 \\
\hline SF10 & 9.76 & 0.08 & -38.6 & 9.83 & 0.41 & -38.2 & 12.35 & 0.43 & -22.3 & 14.90 & 0.23 & -6.3 \\
\hline SF15 & 10.70 & 0.11 & -32.7 & 9.86 & 0.27 & -38.0 & 13.70 & 0.47 & -13.8 & 15.10 & 0.19 & -5.0 \\
\hline NZ10 & 14.10 & 0.51 & -11.3 & 13.20 & 0.45 & -17.0 & 14.30 & 0.09 & -10.1 & 15.10 & 0.34 & -5.0 \\
\hline NZ20 & 18.00 & 0.33 & 13.2 & 15.30 & 0.45 & -3.8 & 17.90 & 0.24 & 12.6 & 18.60 & 0.32 & 17.0 \\
\hline NZ30 & 17.50 & 0.56 & 10.1 & 19.70 & 0.64 & 23.9 & 20.20 & 0.21 & 27.0 & 22.90 & 0.24 & 44.0 \\
\hline
\end{tabular}

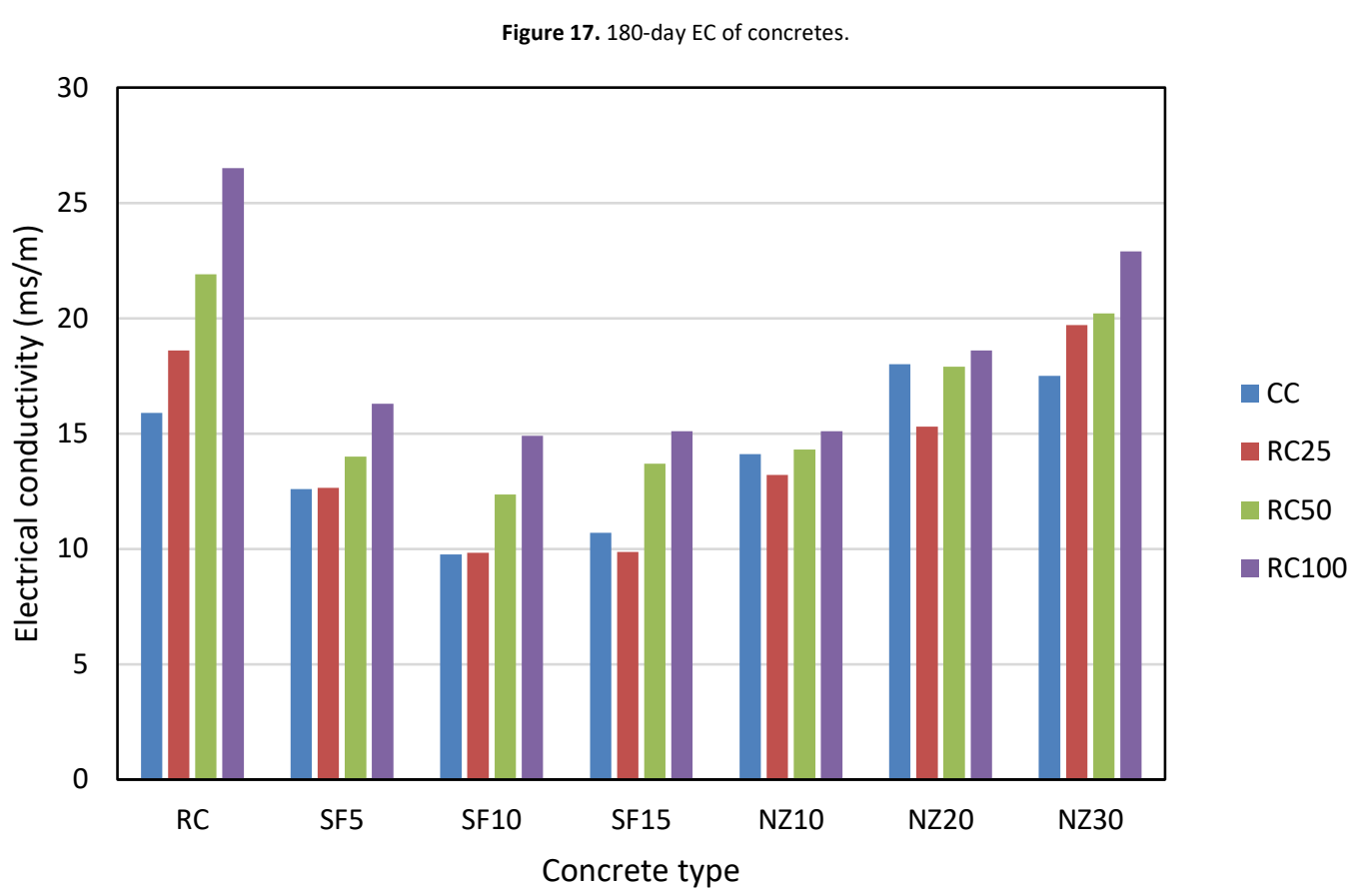

Rapid chloride ion penetration test (RCPT)

The results of RCPT are presented in Table 10 and Fig. 18. Analyzing the results, based on the Table 11, it is observed that CC, RC25, and RC50 have a moderate chloride ion penetration risk. However, compared to CC, there is an impressive resistance of chloride ion reduction for RC100 (86\% higher total charge passed) and making it to fall under the high-risk classification of concrete. Note that some statistical research with $95 \%$ confidence limit showed with a probability of $95 \%$ that the total charge passing through concrete made with 100\% RCCA will increase up to twice as large as that of the CC (Silva 2015). Meanwhile, RC100 with higher or equal chloride ion resistance compared to CC has also been reported (Dhir and Paine 2010, Limbachiya, 2004).

The resistance losses of RAC with elevation of the replacement levels of RCCA can be related to the RCCA nature; compared to NCA, they may contain old adhered mortar with a relatively higher chloride content (Tam and Tam, 2008). On the other hand, the higher dosages of RCCA replacement as well as the higher amount and size of pores and cracks in the concrete lead to easier chloride ion penetration. Nevertheless, due to the use of RCCA without any treatment in non-pozzolan RAC, it is possible for RCCA to release the absorbed water causing higher w/c around ITZ of RCCA and lead less compacted and weaker ITZ. A similar finding was noted by Souche et al. (2017). 
Table 10. 180-day RCPT \pm standard deviation and relative differences to CC (coulomb).

\begin{tabular}{|c|c|c|c|c|c|c|c|c|c|c|c|c|}
\hline & \multicolumn{12}{|c|}{ Aggregates replacement ratio (\%) } \\
\hline & \multicolumn{3}{|c|}{0} & \multicolumn{3}{|c|}{25} & \multicolumn{3}{|c|}{50} & \multicolumn{3}{|c|}{100} \\
\hline & RCPT & SD & $\Delta \%$ & RCPT & SD & $\Delta \%$ & RCPT & SD & $\Delta \%$ & RCPT & SD & $\Delta \%$ \\
\hline $\mathrm{RC}$ & 2246.5 & 26.8 & 0.0 & 2448.7 & 15.3 & 9.0 & 3661.8 & 90.8 & 63.0 & 4169.4 & 63.1 & 85.6 \\
\hline SF5 & 2165.2 & 18.2 & -3.6 & 2349.2 & 41.3 & 4.6 & 2525.0 & 64.2 & 12.4 & 2685.0 & 36.6 & 19.5 \\
\hline SF10 & 1081.0 & 17.7 & -51.9 & 983.7 & 19.4 & -56.2 & 1226.6 & 39.5 & -45.4 & 1725.6 & 38.0 & -23.2 \\
\hline SF15 & 1303.0 & 34.1 & -42.0 & 1145.7 & 21.9 & -49.0 & 1681.1 & 31.7 & -25.2 & 1778.9 & 17.8 & -20.8 \\
\hline NZ10 & 1999.4 & 16.0 & -11.0 & 1774.7 & 61.1 & -21.0 & 1966.8 & 37.8 & -12.5 & 2191.4 & 79.8 & -2.5 \\
\hline NZ20 & 2583.5 & 17.0 & 15.0 & 2156.6 & 40.2 & -4.0 & 2493.6 & 17.1 & 11.0 & 3263.6 & 77.9 & 45.3 \\
\hline NZ30 & 2426.2 & 33.8 & 8.0 & 2875.5 & 17.7 & 28.0 & 3100.2 & 40.9 & 38.0 & 4021.2 & 74.8 & 79.0 \\
\hline
\end{tabular}

Table 11. Chloride ion penetrability of concretes based on charge passed proposed by ASTM C1202.

\begin{tabular}{cc}
\hline Charge passed (coulombs) & Chloride ion penetrability \\
\hline$>400$ & High \\
$2000-4000$ & Moderate \\
$1000-2000$ & Low \\
$100-1000$ & Very low \\
$<100$ & Negligible \\
\hline
\end{tabular}

Figure 18. 180-day RCPT of concretes.

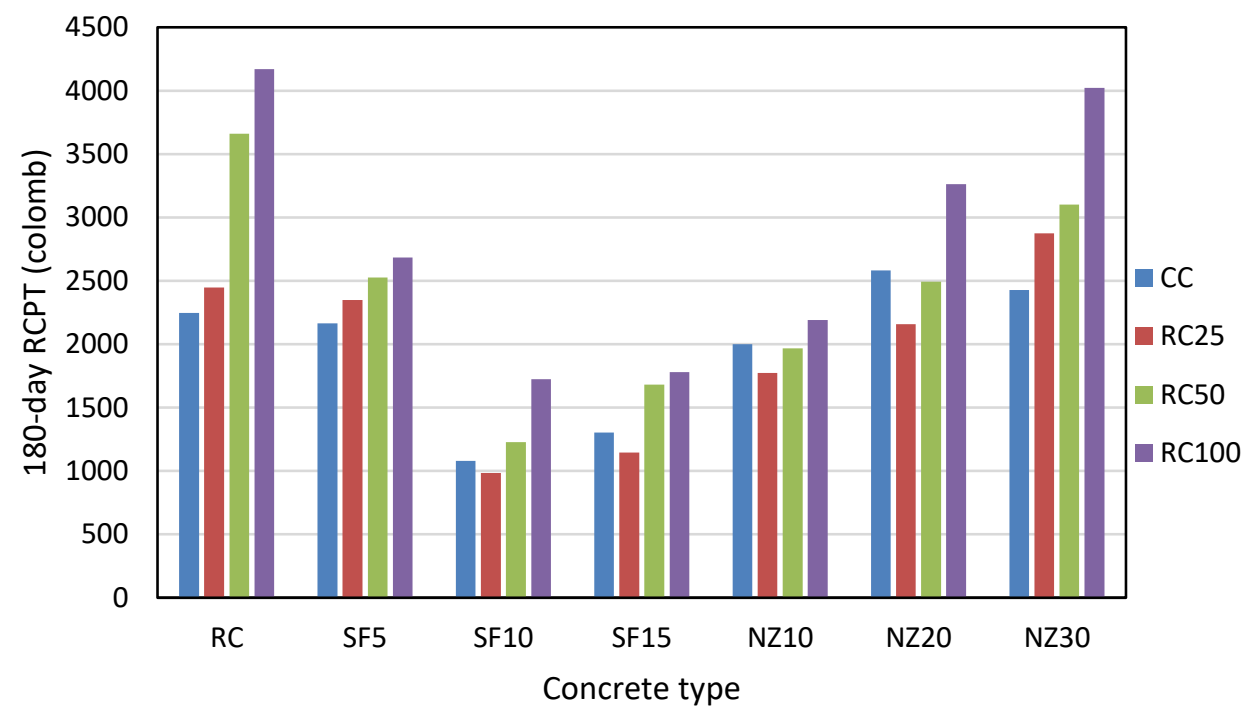

The proper effect of the use of $10 \%$ and $15 \%$ of SF caused all of the CC and RAC cases to place at the quality with low risk of chloride ion penetration. Due to the formation of denser hydration products, the incorporation of $10 \%$ of SF and $25 \%$ of RCCA led to RAC with a very low risk of chloride ion penetration concrete. The results demonstrated that in comparison to RC100, the chloride ion penetration of all RC100 containing SF significantly diminished. This may be attributed to the reduction of the possibility of internal bleeding around RCCA. The reason is that the RCCA was presaturated in SF slurry before mixing and formed a pozzolanic layer around the RCCA. The increment in hydration products formed around the ITZ of RCCA led to a reduction in the release of RCCA absorbed water. Furthermore, the simultaneous effect of higher moisture content of RCCA due to its higher water absorption and presence of higher content of SF around the ITZ of RCCA, caused a complete pozzolanic reaction thereby generating a denser ITZ.

The use of $10 \%$ of NZ showed that up to $50 \%$ replacement of RCCA would lead to production of the RAC with a low risk of chloride ion penetration. Meanwhile, the rest of concretes containing various dosages of NZ were classified as concretes with a moderate risk of penetration. The obtained results of RC100-NZ30 considered it as RAC with a high risk of chloride ion penetration. Fig. 19 plots a linear direct relationship with a relatively good correlation coefficient of 0.87 between 180-day RCPT and 180-day EC. 


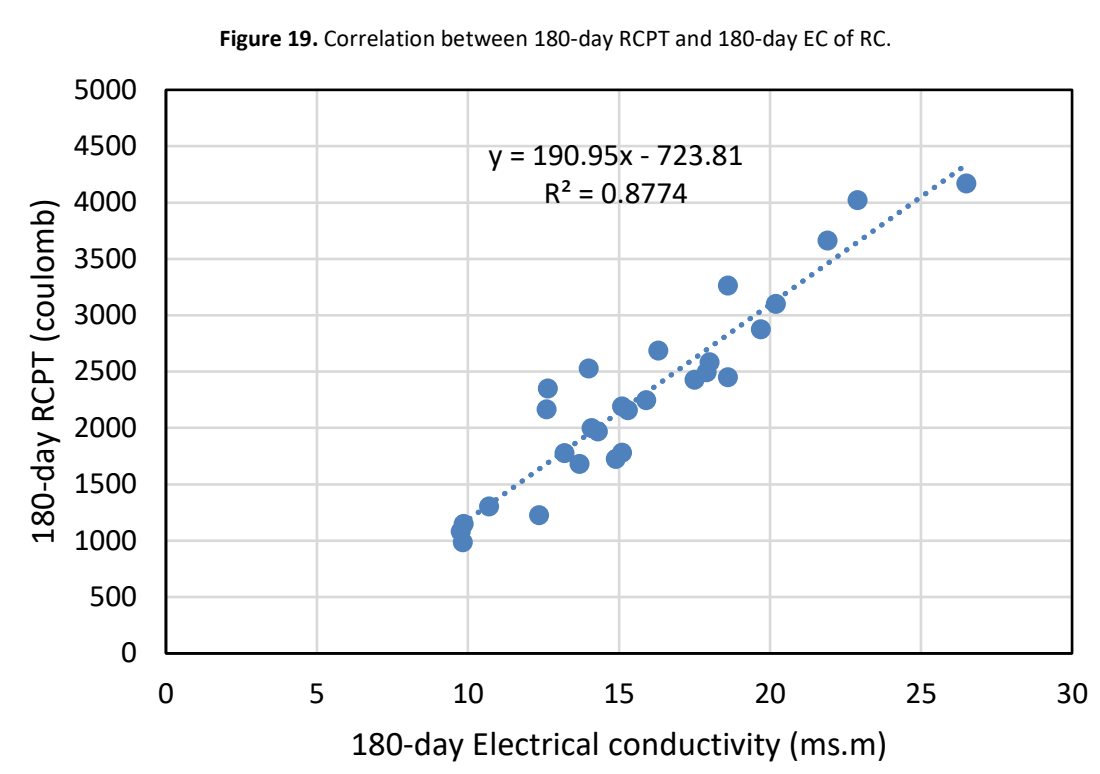

Conclusions

This paper has presented the effect of RCCA on the durability properties of concrete containing SF and NZ. Based on the experimental results and discussions carried out in this study, the following conclusions can be drawn:

- The 28-day CS of the CC was $42.2 \mathrm{MPa}$, while compared to CC, the CS of the remained unchanged. Due to the increase in the amount and size of pores, the 28 -day CS of RC100 decreased by $18 \%$.

- The Pre-saturation of RCCA in SF slurry caused a 17\% higher CS of RC100-SF10 than CC.

- A linear increase of the WAI with the rise of RCCA replacement was seen.

- Compared to CC, the WAI of RC25 did not change significantly; but due to the increase in the amount of attached mortar to the RCCA and the development of porous space, compared to CC, 87\% increment of WAI was seen for RC100.

- Compared to CC, the WAI of RC100-Z10 increased by $74 \%$; while a $43 \%$ increment of WAI was recorded for R100SF10.

- Due to the increase in the size and volume of capillary pores at the higher RCCA replacement, a 91\% increment on WAC was seen, compared to that of CC.

- Compared to CC, WAC of fully RC increased by $57 \%$ and $62 \%$, respectively, at replacement levels of $10 \%$ of SF and $10 \%$ of NZ as the optimal replacement levels for these two pozzolans.

- The SEM analysis showed that increasing the replacement of higher than $10 \%$ of NZ, increases the size and space of pores and discontinuities between hydration products and thus increases WAC in RC containing NZ.

- The ER decreased with an increasing percentage of RCCA replacement.

- Based on the ER criterion, up to $50 \%$ of the RCA, a moderate risk of corrosion was observed, while due to increased water absorption and more cavities in complete replacement of RCA, an imperative risk of corrosion was seen for RC100.

- The favorable effect of the use of SF and NZ can be seen where the use of these two pozzolans caused the imperative risk of corrosion RC100 to become moderate.

- In general, the increase in EC was seen with an increase in RCCA replacement level, however, for concrete containing pozzolans, the rate of EC increment was reduced with an increase in RCCA replacement.

- Compared to CC, the EC of fully RAC containing $5 \%$ to $15 \%$ of SF and $10 \%$ of NZ did not change significantly. This indicates that contrary to the results of WAI and WAC, which were mostly affected by physical changes inside the concrete (size and amount of pores), the EC is more affected by internal chemical changes and the chemical pore solution of the concrete.

- Based on ASTM C1202, a moderate risk of chloride ion penetration was seen for RC50, while compared to CC, an $86 \%$ increase in total charge passed, put the RC100 in the high-risk range of chloride ion penetration.

- According to ASTM C1202, RC25-SF10 was classified as concrete with a very low risk of chloride ion penetration. However, the replacement of $10 \%$ and $15 \%$ of SF puts all RAC's in the category of concretes with low risk of chloride ion penetration.

- Compared to SF, except for the replacement of $10 \%$ of NZ, other replacement levels of NZ showed a weaker behavior, so that RC100-Z30 was in the range of high-risk of chloride ion penetration. 
Ahmadi, B., \& Shekarchi, M. (2010). Use of natural zeolite as a supplementary cementitious material. Cement and Concrete Composites, 32(2), 134141.

Akbarnezhad, A., Ong, K. C. G., Zhang, M. H., \& Tam, C. T. (2013). Acid treatment technique for determining the mortar content of recycled concrete aggregates. Journal of Testing and Evaluation, 41(3), 441-450.

Arredondo-Rea, S. P., Corral-Higuera, R., Gómez-Soberón, J. M., Gámez-García, D. C., Bernal-Camacho, J. M., Rosas-Casarez, C. A., \& Ungsson-Nieblas, M. J. (2019), Durability parameters of reinforced recycled aggregate concrete: Case study. Applied Sciences, 9(4), 617.

ASTM C192 / C192M-16a. (2016), Standard Practice for Making and Curing Concrete Test Specimens in the Laboratory, ASTM International, West Conshohocken.

ASTM C618-19, (2019), Standard Specification for Coal Fly Ash and Raw or Calcined Natural Pozzolan for Use in Concrete, ASTM International, West Conshohocken, PA.

ASTM C 642-13, (2013), Standard Test Method for Density, Absorption, and Voids in Hardened Concretes. ASTM International, West Conshohocken, $P A$.

ASTM C1202-12, (2012), Standard Test Method for Electrical Indication of Concrete's Ability to Resist Chloride Ion Penetration, ASTM International, West Conshohocken, PA.

ASTM C1585, (2011), Standard Test Method for Measurement of Rate of Absorption of Water by Hydraulic-Cement Concretes. ASTM International, West Conshohocken, PA.

ASTM C1760-12, (2012), Standard Test Method for Bulk Electrical Conductivity of Hardened Concrete, ASTM International, West Conshohocken, PA.

Browne, R. D. (1991). Field investigations: site \& laboratory tests: maintenance repair and rehabilitation of concrete structures. CEEC, Lisboan.

BS 1881: 116 (1983). Methods for the Determination of Compressive Strength of Concrete. BSI, Linfordwood, Milton Keynes MK14 6LE, UK.

Cheng-Yi, H., \& Feldman, R. F. (1985). Hydration reactions in Portland cement-silica fume blends. Cement and Concrete Research, 15(4), 585-592.

Corral-Higuera R., Arredondo-Rea S. P., Neri-Flores M. A., Gomez-Soberon J. M., Almaral- Sanchez J. L., Castorena-Gonzalez J. H., Martinez-Villafane A., \& Almeraya-Calderon F. (2011). Chloride ion penetrability and corrosion behavior of steel in concrete with sustainability

De Juan, M. S., \& Gutiérrez, P. A. (2009). Study on the influence of attached mortar content on the properties of recycled concrete aggregate. Construction and Building Materials, 23(2), 872-877.

Dhir, R. K., \& Paine, K. A. (2010). Value added sustainable use of recycled and secondary aggregates in concrete. Indian Concrete Journal, 84(3), 7-26.

Etxeberria, M., Vázquez, E., Marí, A., \& Barra, M. (2007). Influence of amount of recycled coarse aggregates and production process on properties of recycled aggregate concrete. Cement and concrete research, 37(5), 735-742.

González-Fonteboa, B., Seara-Paz, S., De Brito, J., González-Taboada, I., Martínez-Abella, F., \& Vasco-Silva, R. (2018). Recycled concrete with coarse recycled aggregate. An overview and analysis. Materials de construction, 68(330), 151.

Hall, C. (1989). Water sorptivity of mortars and concretes: a review. Magazine of concrete research, 41(147), 51-61.

Hansen, T. C. (1992). "Recycling of Demolished Concrete and Masonry". CRC Press.

Hannesson, G., Kuder, K., Shogren, R., \& Lehman, D. (2012). The influence of high volume of fly ash and slag on the compressive strength of selfconsolidating concrete. Construction and Building Materials, 30, 161-168.

Hobbs, D. W. (1999). Aggregate influence on chloride ion diffusion into concrete. Cement and Concrete Research, 29(12), 1995-1998.

ICC, (2003). Iranian Concrete Code (ICC). Iranian Management Organization, 6 ed., Tehran, Iran.

Jalilifar, H., Sajedi, F., \& Afshar, R. (2016). Experimental effect of using silica fume and fly ash on mechanical properties of recycled concretes. International Journal of Engineering and Applied Sciences, 3(11).

Kanellopoulos, A., Nicolaides, D., \& Petrou, M. F. (2014). Mechanical and durability properties of concretes containing recycled lime powder and recycled aggregates. Construction and Building Materials, 53, 253-259.

Kisku, N., Joshi, H., Ansari, M., Panda, S. K., Nayak, S., \& Dutta, S. C. (2017). A critical review and assessment for usage of recycled aggregate as sustainable construction material. Construction and Building Materials, 131, 721-740.

Kong D.; Lei T.; Zheng J.; Ma C.; Jiang J.; Jiang J. (2010). Effect and mechanism of surface coating pozzalanics materials around aggregate on properties and ITZ microstructure of recycled aggregate concrete. Construction and Building Materials, 24(5), 701-708.

Kou S. C.; Poon C. S. (2009.). A comparative study of using river sand, crushed fine stone, furnace bottom ash and fine recycled aggregate as fine aggregates for concrete production". Presented at Excellence in Concrete Construction through Innovation, pp. 459-464.

Kou S. C.; Poon C. S. (2012). Enhancing the durability properties of concrete prepared with coarse recycled aggregate. Construction and Building Materials, 35, pp. 69-76.

Kurda, R., de Brito, J., \& Silvestre, J. D. (2019). Water absorption and electrical resistivity of concrete with recycled concrete aggregates and fly ash. Cement and Concrete Composites, 95, 169-182. 
Kwan, W. H., Ramli, M., Kam, K. J., \& Sulieman, M. Z. (2012). "Influence of the amount of recycled coarse aggregate in concrete design and durability properties". Construction and Building Materials, 26(1), 565-573.

Limbachiya, M. C. (2004, June). Coarse recycled aggregates for use in new concrete. In Proceedings of the Institution of Civil Engineers-Engineering Sustainability, 157(2), 99-106. Thomas Telford Ltd.

Limbachiya M., Meddah M. S. \& Ouchagour Y. (2012) - "Performance of Portland/silica fume cement concrete produced with recycled concrete aggregate". ACI Materials Journal, 109(1), pp. 91-100.

Majhi, R.K., \& Nayak, A.N. (2019). Bond, durability and microstructural characteristics of ground granulated blast furnace slag based recycled aggregate concrete. Constr. Build. Mater. 212, 578-595.

Malhotra, V. M., \& Carino, N. J. (2003). “Handbook on nondestructive testing of concrete”. CRC press.

Matias, D., de Brito, J., Rosa, A., \& Pedro, D. (2013). Durability of concrete with recycled coarse aggregates: influence of superplasticizers. Journal of Materials in Civil Engineering, 26(7), 06014011.

Mehta, P. K., \& Monteiro, P. J. (2006). Concrete: microstructure, properties, and materials (No. Sirsi) i9780071462891).

Oikonomou, N. D. (2005). Recycled concrete aggregates. Cement and concrete composites, 27(2), 315-318.

Naiqian, F., \& Tingyu, H. (1998). Mechanism of natural zeolite powder in preventing alkali-silica reaction in concrete. Advances in cement research, 10(3), 101-108.

Pan, Z., Zhou, J., Jiang, X., Xu, Y., Jin, R., Ma, J., \& Chen, W. (2019). Investigating the effects of steel slag powder on the properties of self-compacting concrete with recycled aggregates. Construction and Building Materials, 200, 570-577.

Pedro, D., De Brito, J., \& Evangelista, L. (2018). Durability performance of high-performance concrete made with recycled aggregates, fly ash and densified silica fume. Cement and Concrete Composites, 93, 63-74.

Sasanipour, H., \& Aslani, F. (2020). Durability properties evaluation of self-compacting concrete prepared with waste fine and coarse recycled concrete aggregates. Construction and Building Materials, 236, 117540.

Silva, R. (2015). "Use of recycled aggregates from construction and demolition wastes in the production of structural concrete". Department of Civil Engineering, Architecture and Georesources. Instituto Superior Tecnico, Lisboa, Portugal.

Souche, J. C., Devillers, P., Salgues, M., \& Diaz, E. G. (2017). Influence of recycled coarse aggregates on permeability of fresh concrete. Cement and Concrete Composites, 83, 394-404.

Tam, V. W., Gao, X. F., \& Tam, C. M. (2005). "Microstructural analysis of recycled aggregate concrete produced from two-stage mixing approach". Cement and concrete research, 35(6), 1195-1203.

Tam, V. W., \& Tam, C. M. (2008). "Diversifying two-stage mixing approach (TSMA) for recycled aggregate concrete: TSMAs and TSMAsc". Construction and Building Materials, 22(10), 2068-2077.

Thomas, C., Setién, J., Polanco, J., Alaejos, P. \& De Juan, M.S. (2013). Durability of recycled aggregate concrete. Construction and Building Materials, 40, 1054-1065.

Tu T.-Y., Jann Y.-Y. \& Hwang C.-L. (2005). The application of recycled aggregates in SCC. Presented at the 1st International Symposium on Design, Performance and Use of Self- Consolidating Concrete, pp. 145-152.

Wu, B., \& Ye, G. (2017). Development of porosity of cement paste blended with supplementary cementitious materials after carbonation. Construction and Building Materials, 145, 52-61.

Younis, K. H., \& Pilakoutas, K. (2013). "Strength prediction model and methods for improving recycled aggregate concrete". Construction and Building Materials, 49, 688-701.

Zhu, P., Hao, Y., Liu, H., Wei, D., Liu, S., \& Gu, L. (2019). Durability evaluation of three generations of $100 \%$ repeatedly recycled coarse aggregate concrete. Construction and Building Materials, 210, 442-450.

Zhu, X., Chen, X., Shen, N., Tian, H., Fan, X. and Lu, J. (2018). "Mechanical properties of pervious concrete with recycled aggregate". Computers and Concrete, 21(6), 623-635.

Zhu, Y. G., Kou, S. C., Poon, C. S., Dai, J. G., \& Li, Q. Y. (2013). Influence of silane-based water repellent on the durability properties of recycled aggregate concrete. Cement and Concrete Composites, 35(1), 32-38. 